\title{
Digestibilidade Aparente e Trânsito Gastrintestinal em Tilápia do Nilo (Oreochromis niloticus), em Função da Fibra Bruta da Dieta ${ }^{1}$
}

\author{
Eduardo Arruda Teixeira Lanna ${ }^{2}$, Luiz Edivaldo Pezzato ${ }^{3}$, Paulo Roberto Cecon ${ }^{4}$, Wilson \\ Massamitu Furuya ${ }^{5}$, Marcos Antonio Delmondes Bomfim ${ }^{6}$
}

RESUMO - Os efeitos de diferentes níveis de fibra bruta na digestibilidade aparente e velocidade de trânsito gastrintestinal de tilápias do Nilo alimentadas com dietas purificadas fornecidas foram avaliados. Utilizaram-se cinco aquários circulares (250 L) para alimentação, dotados de sistema fechado de filtragem, reabastecimento e aquecimento da água, e cinco aquários de digestibilidade (100 L), dotados de sistema individual de filtragem, reabastecimento e aquecimento. Utilizaram-se 32 peixes por aquário, com peso inicial médio de 30,65 $\pm 0,50 \mathrm{~g}$. Adotou-se o delineamento inteiramente casualizado caracterizado por cinco níveis de fibra bruta (2,5; 5,0; 7,5; 10,0 e 12,5\%) e 5 repetições. Concluiu-se que níveis crescentes de fibra bruta, em dietas purificadas, interferem significativamente na digestibilidade aparente da matéria seca, proteína bruta e do extrato etéreo. Níveis de até 5,00\% de fibra bruta não diminuiu a digestibilidade aparente da matéria seca e da proteína bruta e 7,50\% de fibra bruta não diminuiu a digestibilidade aparente do extrato etéreo da dieta purificada pela tilápia do Nilo. Entretanto, o aumento do teor de fibra bruta da dieta diminui significativamente o tempo de trânsito gastrintestinal.

Palavras-chave: digestibilidade, fibra bruta, nutrição de peixes, tilápia do Nilo, velocidade de trânsito

\section{Apparent Digestibility and Gastrointestinal Transit in Nile Tilapia (Oreochromis niloticus) in Function ofthe Dietary Crude Fiber}

\begin{abstract}
The objective of this study was to evaluate, in purified diets, the effects of different levels of crude fiber on the apparent digestibility and gastrointestinal transit rate in Nile Tilapia. Five circular fishbowls (250 L) with a closed system of water filtering, replenishment and heat for feeding and five digestibility fishbowls with individual filtering replenishment and heat system were used. Thirty-two fishes, averaging initial weight of $30.65 \pm 0.50$ were used. A completely randomized design with five levels of crude fiber $(2.5,5.0,7.5,10.0$, and $12.5 \%)$ and five replicates was used. It was concluded that increasing levels of crude fiber in purified diets significantly affect the apparent digestibility of dry matter, crude protein and ether extract. Levels up to $5.0 \%$ crude fiber did not reduce the apparent digestibility of dry matter and crude protein and levels up to 7.5\% crude fiber did not reduce the apparent digestibility of ether extract of purified diet in Nile tilapia. However, the increase of dietary crude protein significantly reduce the gastrointestinal transit rate.
\end{abstract}

Key Words: crude fiber, digestibility, fish feeding, Nile tilapia, transit rate

\section{Introdução}

Na piscicultura, para se obter melhor eficiência alimentar, é necessária a integração de fatores como características fisiológicas, hábito alimentar e exigência nutricional da espécie em cultivo, além da composição química e da disponibilidade de nutrientes dos ingredientes selecionados para a confecção da ração completa.

Embora a fibra bruta esteja presente na dieta natural da maioria dos peixes, existem poucos estudos sobre sua função. As características físico-químicas e seu papel devem ser considerados na formulação da ração. Seu teor dependerá da viabilidade de processamento e das limitações metabólicas e fisiológicas das espécies.

Fibra refere-se aos componentes vegetais indigeríveis incluídos na ração de peixes como parte inerte e de valor nutritivo insignificante (Hilton, 1983; Shiau et al., 1988). Segundo Silva (1990), engloba as frações de celulose, hemicelulose, lignina e pectina.

Segundo Anderson et al. (1984), a fibra bruta é usada para ajustar os níveis de nutrientes das rações experimentais. A fibra altera a taxa de utilização dos nutrientes por modificar o tempo de esvaziamento

\footnotetext{
${ }^{1}$ Parte da tese de Doutorado do primeiro autor apresentada à UNESP-Botucatu-SP.

2 Prof. Dr., Depto. de Zootecnia/UFV, MG, Brasil (elanna@ufv.br).

3 Prof. Dr., Depto. Melh. e Nutr. Animal - UNESP - Botucatu, SP (epezzato@fca.unesp.br).

${ }^{4}$ Prof. Dr., Depto. de Informática/UFV, MG, Brasil (cecon@dpi.ufv.br).

${ }^{5}$ Prof. Dr., Depto. de Zootecnia/UEM, PR, Brasil (furuya@wnet.com.br)

${ }^{6}$ Doutorando, Depto. de Zootecnia/UFV, MG, Brasil (madbomfim@hotmail.com).
} 
gástrico, agir na motilidade e trânsito intestinal, atuar na atividade de enzimas digestivas, pela captação de micelas de lipídios, e graças à interação com a superfície da parede intestinal, interferir na absorção de nutrientes (Madar \& Thorne, 1987). Esses autores afirmam que podem interferir na digestibilidade dos nutrientes, destacando a proteína, os carboidratos e os lipídeos.

Hilton et al. (1983), em estudo realizado com trutas arco-íris (Salmo gairdneri), peso médio de $5,30 \pm 0,20 \mathrm{~g}$, observaram que rações com altos teores de fibra bruta resultaram em decréscimo no esvaziamento gástrico, em decorrência de menor ingestão e digestibilidade de todos os nutrientes.

Pereira Filho (1989), em estudo com a carpa comum (Cyprinus carpio), obteve coeficientes de digestibilidade aparente para a proteína bruta entre 75,8 e 89,7\%, quando combinou diferentes níveis de fibra e proteína (19,0; 24,0 e 28,0\%), destacando que os índices de digestibilidade mais altos foram proporcionados pelas rações com $28,0 \%$ de proteína e níveis mais baixos de fibra bruta. Dioundick \& Stom (1990) realizaram um experimento com tilápias (Oreochromis mossambicus), peso médio de $2,5 \mathrm{~g}$, alimentadas com rações contendo $49,5 \%$ de proteína bruta e níveis de 0,0; 2,5; 5,0; 7,5 e 10,0\% de celulose, e concluíram que as melhores respostas de crescimento, conversão alimentar e eficiência protéica foram obtidas com $2,5 \%$ e $5,0 \%$ de celulose, enquanto as piores foram resultantes das rações com $0,0 \%$ e 10,0\% de celulose.

Tendo por objetivo avaliar a ação da fibra sobre o desempenho da piracanjuba (Brycon

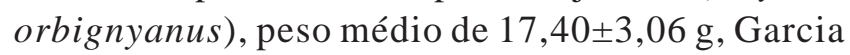
(1998) empregou rações contendo 32,0\% de proteína bruta, $3.300 \mathrm{kcal}$ ED/kg de ração e níveis crescentes de fibra bruta $(5,0 ; 7,0 ; 8,0$ e 9,0\%). Segundo esse autor, o melhor resultado foi proporcionado pelas rações com teores mais elevados de fibra bruta. Concluiu, ainda, que os teores mais elevados de fibra resultaram em piores coeficientes de digestibilidade aparente da proteína bruta e em menores tempos médios de permanência da ingesta no sistema digestório.

Resposta semelhante foi obtida por Dupree \& Sneed (1966), quando testaram cinco níveis de celulose em dietas purificadas para bagre de canal (Ictalurus punctatus). Esses autores observaram menor taxa de crescimento com a dieta isenta de celulose e melhor crescimento, à medida que se elevaram os teores dietários de celulose, sendo o melhor ganho de peso obtido com o nível de 21,0\%.

Confirmando essa tendência, Zanoni (1996) observou melhores resultados de ganho de peso, eficiência alimentar e conversão alimentar com 9,0\% de fibra bruta em juvenis de pacus (Piaractus

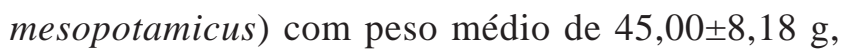
alimentados com rações contendo 3,0; 5,0; 7,0 e 9,0\% de fibra bruta. Constatou-se aumento na velocidade de trânsito gastrintestinal, porém o consumo relativo de ração, a taxa de eficiência protéica e a composição da carcaça não foram afetados.

Esta pesquisa foi desenvolvida com o objetivo de determinar os efeitos da fibra bruta na digestibilidade aparente e na velocidade de trânsito gastrintestinal de tilápia do Nilo alimentadas com dietas purificadas.

\section{Material e Métodos}

Este estudo foi conduzido no Laboratório de Nutrição de Organismos Aquáticos da FMVZ, Campus de Botucatu, unidade integrada ao Centro de Aqüicultura da UNESP, no período de 18/12 a 12/02/99.

Foram confeccionadas cinco dietas purificadas (Tabela 1) segundo as normas apresentadas pelo NRC (1993). Variaram-se os níveis de inclusão de fibra bruta $(2,50 ; 5,00 ; 7,50 ; 10,00$ e $12,50 \%)$, caracterizando, respectivamente, os tratamentos T 2,5 (2,50\% de FB), T 5,0 (5,00\% de FB), T 7,5 (7,50\% de FB), T $10,0(10,00 \%$ de FB) e T 12,5 (12,50\% de FB). Para determinação do coeficiente de digestibilidade aparente, foi acrescido $0,1 \%$ de óxido de crômio-III.

Na confecção das dietas, os ingredientes foram moídos a granulometria padrão de $0,43 \mathrm{~mm}$ de diâmetro, misturados manualmente e peletizados. Posteriormente, os péletes foram desidratados em estufa dotada de ventilação forçada a $55^{\circ} \mathrm{C}$ por 24 horas. Finalmente, os péletes foram fracionados e peneirados para obterem-se diâmetros de 3,36 mm.

Os coeficientes de digestibilidade aparente (CDA) foram determinados pelo método indireto usando óxido de crômio como marcador inerte. Utilizaram-se cinco aquários de alimentação de formato circular (250 L) e cinco aquários para coleta de fezes, com formato cônico e capacidade de 100 litros, também confeccionados em fibra de vidro. Cento e sessenta juvenis de tilápia do Nilo (Oreochromis niloticus), 32 por aquário, com peso médio de 30,65 \pm 0,50 g, foram alojados em cinco tanques-rede de formato circular, confeccionado com tela plástica (malha de

R. Bras. Zootec., v.33, n.6, p.2186-2192, 2004 (Supl. 3) 
Tabela 1 - Composição percentual das dietas experimentais

Table 1 - Percentage composition of the experimental diets

\begin{tabular}{|c|c|c|c|c|c|}
\hline \multirow[t]{2}{*}{$\begin{array}{l}\text { Ingrediente (\%) } \\
\text { Ingredient (\%) }\end{array}$} & \multicolumn{5}{|c|}{$\begin{array}{c}\text { Tratamento* } \\
\text { Treatment }\end{array}$} \\
\hline & $\mathrm{T} 2,5$ & $\mathrm{~T} 5,0$ & $\mathrm{~T} 7,5$ & $\mathrm{~T} 10,0$ & $\mathrm{~T} 12,5$ \\
\hline Albumina (Albumin) & 37,88 & 36,53 & 35,00 & 33,87 & 32,40 \\
\hline Gelatina (Gelatine) & 5,00 & 5,00 & 5,00 & 5,00 & 5,00 \\
\hline Dextrose (Dextrin) & 44,48 & 42,65 & 41,01 & 38,96 & 37,25 \\
\hline Celulose (Cellulose) & 3,18 & 6,35 & 9,53 & 12,70 & 15,88 \\
\hline Óleo de soja (Soybean oil) & 5,00 & 5,00 & 5,00 & 5,00 & 5,00 \\
\hline Fosfato bicálcico (Dicalcium phosphate) & 3,80 & 3,80 & 3,80 & 3,80 & 3,80 \\
\hline BHT (antioxidante) (Antioxidant) & 0,02 & 0,02 & 0,02 & 0,02 & 0,02 \\
\hline Supl. vitam. mineral ${ }^{1}$ (Vit.min.supplement) & 0,50 & 0,50 & 0,50 & 0,50 & 0,50 \\
\hline Vitamina C & 0,05 & 0,05 & 0,05 & 0,05 & 0,05 \\
\hline $\mathrm{Cr}_{2} \mathrm{O}_{3}$ & 0,10 & 0,10 & 0,10 & 0,10 & 0,10 \\
\hline Total & 100,00 & 100,00 & 100,00 & 100,00 & 100,00 \\
\hline \multicolumn{6}{|l|}{ Valores calculados } \\
\hline \multicolumn{6}{|l|}{ Calculated values } \\
\hline Proteína bruta, \% (Crude protein , \%) & 36,57 & 35,43 & 34,13 & 33,17 & 31,92 \\
\hline Extrato etéreo, \% (Ether extract, \%) & 5,00 & 5,00 & 5,00 & 5,00 & 5,00 \\
\hline Fibra bruta, \% (Crude fiber, \%) & 2,50 & 5,00 & 7,51 & 10,00 & 12,51 \\
\hline Cálcio, \% (Calcium, \%) & 0,40 & 0,40 & 0,40 & 0,40 & 0,40 \\
\hline Fósforo disponível, \% (Available phophorus, \%) & 0,61 & 0,61 & 0,61 & 0,61 & 0,61 \\
\hline ED, kcal/kg (DE, kcal/kg) & 3541 & 3432 & 3321 & 3215 & 3104 \\
\hline Relação ED:PB (DE:CP ratio) & 97 & 97 & 97 & 97 & 97 \\
\hline
\end{tabular}

${ }^{1}$ Suplemento vitamínico e mineral (Min. and vit. supplement) (Supremais) níveis de garantia/kg do produto: vit. A,600000 UI; vit. D 100000 UI; vitE,6000 mg; vit. $K_{3}, 1200$ mg; vit. $B_{1}, 2400$ mg; vit. $B_{2} 2400$ mg; vit. $B_{6}, 24000$ mg; $B_{12}, 2400$ mg; ác. fólico (folic acid), 600 mg; ác. pantotênico (panthotenic acid), $6000 \mathrm{mg}$; vit. C, 24 g; biotina (biotin), $24 \mathrm{mg}$; colina (cholin), $54 \mathrm{~g}$; niacina (niacin), $12000 \mathrm{mg} ; \mathrm{Fe}, 5000 \mathrm{mg} ; \mathrm{Cu}, 300 \mathrm{mg} ; \mathrm{Mn}$, 2000 mg; Zn, 3000 mg; I, 10 mg; Co,1 mg; Se,10 mg.

* Refere-se aos níveis percentuais da inclusão da fibra bruta (Levels of crude fiber, \%).

$1,5 \mathrm{~cm}$ entre-nós). Estes foram utilizados para abrigar os peixes e facilitar o manejo de alimentação e a coleta de fezes, sem estressá-los, conforme metodologia adotada nesse laboratório.

Os peixes foram mantidos, durante o dia, nos aquários de alimentação, onde receberam refeições à vontade das $8 \mathrm{~h}$ às $17 \mathrm{~h} 30$. Após, foram transferidos para os tanques de coleta de fezes, onde permaneceram até a manhã do dia subseqüente. Esses tanques, dotados de sistema de coleta de fezes por gravidade, possibilitaram a obtenção do material para análise. Após o período de alimentação e de coleta de fezes, efetuou-se limpeza dos tanques, preparando-os para nova coleta (repetição). O período de coleta de fezes de cada tratamento foi de cinco dias. As fezes foram centrifugadas a $6000 \mathrm{rpm} / \mathrm{min}$, descartando a fase líquida, desidratadas em estufa de ventilação forçada a $55^{\circ} \mathrm{C}$, moídas e armazenadas a $-20^{\circ} \mathrm{C}$, para posterior análise.

A temperatura da água dos aquários foi aferida às 8h e 16h; o controle do $\mathrm{pH}$ e do teor de oxigênio dissolvido na água a cada sete dias, respectivamente, por um potenciômetro e pelo método de Winkler modificado pela adição de azida sódica, conforme recomendado por Boyd (1984), e a amônia total.

Os coeficientes de digestibilidade aparente foram obtidos, empregando-se o método indireto, com o marcador óxido de crômio-III, de acordo com a metodologia descrita por Austreng (1978). A determinação da concentração do óxido crômico foi realizada pelo método da absorção atômica (Willians et al., 1962), utilizando-se o aparelho GBC Avante E Atomic Absorpition Spectrometer, e o coeficiente de digestibilidade aparente calculado segundo Nose (1966).

$$
\mathrm{Da}_{(\mathrm{n})}=100-\left[100\left(\frac{\% \mathrm{Cr}_{2} \mathrm{O}_{3 \mathrm{r}}}{\% \mathrm{Cr}_{2} \mathrm{O}_{3 \mathrm{f}}}\right) \times\left(\frac{\% \mathrm{~N}_{\mathrm{f}}}{\% \mathrm{~N}_{\mathrm{r}}}\right)\right]
$$

em que $\mathrm{Da}_{(\mathrm{n})}=$ digestibilidade aparente do nutriente; $\mathrm{Cr}_{2} \mathrm{O}_{3 \mathrm{r}}=\%$ de óxido de crômio na ração; $\mathrm{Cr}_{2} \mathrm{O}_{3 \mathrm{f}}=$ \% de óxido de crômio nas fezes; $\mathrm{N}_{\mathrm{r}}=\%$ nutrientes na ração; $\mathrm{N}_{\mathrm{f}}=\%$ nutriente nas fezes.

O delineamento experimental adotado foi o inteiramente casualizado caracterizado por cinco níveis de fibra bruta $(2,50 ; 5,00 ; 7,50 ; 10,00$ e 12,50\%), cinco repetições para coeficiente de digestibilidade aparen- 
te e oito repetições para velocidade de trânsito gastrintestinal. Os dados foram interpretados por meio de análises de variância e de regressão. As médias dos fatores qualitativos foram comparadas pelo teste Tukey, adotando-se nível de 5\% de probabilidade. Para os fatores quantitativos, os modelos foram escolhidos com base na significância dos coeficientes de regressão utilizando-se o teste $F$, a $5 \%$ de probabilidade, no coeficiente de determinação e no fenômeno em estudo.

O estudo da velocidade de trânsito gastrintestinal foi realizado segundo o método descrito por Storebakken (1985), com algumas adaptações, utilizando-se cinco aquários circulares $(250 \mathrm{~L})$, e teve início três dias após o término da avaliação do coeficiente de digestibilidade, tempo necessário para eliminar os prováveis efeitos do estresse causado pelo manejo.

Os peixes receberam as dietas dos diferentes tratamentos (Tabela 1), sendo o marcador da digestibilidade (óxido de crômio-III cor verde) substituído pela mesma quantidade de óxido de titânio-II (cor branca). Adotou-se o mesmo regime alimentar do estudo da digestibilidade e foram obtidas oito análises (repetições) de velocidade de trânsito.

As fezes foram coletadas em intervalos de 30 minutos, a partir das $8 \mathrm{~h}$, logo após o fornecimento das dietas. Após a coleta, as fezes foram transferidas para placas-de-petri, no sentido de melhor visualizar a mudança de cor verde para branca. A cada observação, estabeleceu-se como critério a presença de 100,00\% de fezes com coloração branca.

\section{Resultados e Discussão}

O sistema de reabastecimento, através de biofiltro, possibilitou aeração uniforme e a renovação total da água dos aquários a cada 1 hora, mantendo a temperatura da água sob controle. Os valores médios de temperatura $\left(26,5 \pm 0,99^{\circ} \mathrm{C}\right), \mathrm{pH}(7,05 \pm 0,07)$, oxigênio dissolvido (5,80 $\pm 0,74 \mathrm{mg} / \mathrm{L})$ e amônia total $(0,023 \pm 0,02$ ppm), obtidos durante o período experimental, mantiveram-se dentro da faixa recomendada por Castagnolli \& Cyrino (1986).

Na Tabela 2, encontram-se os valores médios dos coeficientes de digestibilidade aparente (CDA) e os índices relativos de comparação (IRC) aplicados as médias dos CDA da matéria seca, proteína bruta e extrato etéreo, obtidos com as tilápias do Nilo, em função dos diferentes níveis de fibra bruta na dieta purificada.

Observa-se que, para a matéria seca, os resultados de digestibilidade revelaram efeito significativo $(\mathrm{P}<0,01)$ para tratamentos. Essas médias, quando comparadas pelo teste Tukey, revelaram que os CDA dos tratamentos T 2,5 e T 5,0 não diferiram entre si, ocorrendo o mesmo entre os tratamentos $\mathrm{T}$ 7,5 e T 10,0; estes dois grupos diferiram entre si $(\mathrm{P}<0,05)$ e do $\mathrm{T} 12,5$. Constata-se, ainda, que a fibra bruta resultou em efeito linear decrescente de digestibilidade da MS $(\mathrm{P}<0,05)$ com a equação $\mathrm{Y}=97,8738-1,8567 \mathrm{FB}$, com coeficiente de determinação de $98 \%$.

No sentido de melhor visualizar o efeito da fibra bruta no coeficiente de digestibilidade aparente da matéria seca, aplicou-se o índice relativo de comparação (IRC), sendo atribuído ao T 5,0 o índice 100,00\% (Tabela 2). Assim, pode-se observar que o tratamento T 2,5 mostrou-se melhor (2,65\%) e que os tratamentos T 7,5; T 10,0 e T 12,5 apresentaram piores CDA, respectivamente, em 6,21; 10,31 e 18,06\%.

Estes resultados corroboram os obtidos por Hilton et al. (1983) em estudo realizado com trutas. Esses autores observaram que os teores de fibra bruta em níveis de 10,0\% a 20,0\% diminuem o coeficiente de digestibilidade dos nutrientes da ração, enquanto Shiau et al. (1988) afirmam que níveis acima de 10\% CMC diminuem o coeficiente de digestibilidade da matéria seca.

Os resultados de digestibilidade da proteína bruta das diferentes dietas (Tabela 2) revelaram efeito significativo $(\mathrm{P}<0,01)$ para os tratamentos. Comparando-se essas médias pelo teste Tukey, observa-se que os tratamentos T 2,5; T 5,0 e T 10,0 apresentaram CDA semelhantes. O mesmo não ocorreu entre os tratamentos T 7,5 e T 12,5. Constatou-se, por intermédio da análise de regressão, efeito quadrático $(\mathrm{P}<0,05)$ dos níveis de fibra bruta sobre os coeficientes de digestibilidade da proteína bruta, com a equação $\mathrm{Y}=96,7692+0,2044 \mathrm{FB}-0,0205 \mathrm{FB}^{2}$, com coeficiente de determinação de $68 \%$.

Aplicando-se o índice relativo de comparação (IRC) às médias dos coeficientes de digestibilidade aparente da proteína bruta, atribuindo-se o índice $100,00 \%$ ao tratamento T 5,0 (Tabela 2), observa-se que os tratamentos T 2,5; T 7,5; T 10,0 e T 12,5 apresentaram menores CDA, respectivamente, de $-0,60 ;-0,97 ;-0,64$ e $-1,59 \%$.

O coeficiente de digestibilidade aparente da proteína bruta aumentou até o nível de 4,98\% de fibra 
Tabela 2 - Valores médios dos coeficientes de digestibilidade aparente (\%) e índices relativos de comparação (IRC) da matéria seca, proteína bruta e extrato etéreo, em função dos níveis de fibra bruta na dieta

Table 2 - Average values for digestibility coefficients, in percent and comparation relative index (CRI) of dry matter, crude protein, ether extrac, in function of the dietary crude fiber levels

\begin{tabular}{|c|c|c|c|c|c|c|}
\hline \multirow[t]{2}{*}{ Fração (\%) } & \multicolumn{5}{|c|}{$\begin{array}{c}\text { Tratamento } \\
\text { Treatment }\end{array}$} & \multirow[t]{2}{*}{ CV\% } \\
\hline & $\mathrm{T} 2,5$ & $\mathrm{~T} 5,0$ & $\mathrm{~T} 7,5$ & $\mathrm{~T} 10,0$ & $\mathrm{~T} 12,5$ & \\
\hline $\begin{array}{l}\text { Matéria seca } \\
\text { Dry matter }\end{array}$ & $92,06 \mathrm{a}( \pm 0,84)$ & $89,68 \mathrm{a}( \pm 2,49)$ & $84,11 b( \pm 0,51)$ & $80,43 b( \pm 0,98)$ & $73,48 c( \pm 4,92)$ & 3,03 \\
\hline IRC (\%) & 2,65 & 100,00 & $-6,21$ & $-10,31$ & $-18,06$ & \\
\hline $\begin{array}{l}\text { Proteína bruta } \\
\text { Crude protein }\end{array}$ & $97,25 \mathrm{ab}( \pm 0,40)$ & $97,84 \mathrm{a}( \pm 0,56)$ & $96,89 \mathrm{bc}( \pm 0,21)$ & $97,21 \mathrm{ab}( \pm 0,14)$ & $96,28 c( \pm 0,69)$ & 0,46 \\
\hline IRC (\%) & $-0,60$ & 100,00 & $-0,97$ & $-0,64$ & $-1,59$ & \\
\hline $\begin{array}{l}\text { Extrato etéreo } \\
\text { Ether extract }\end{array}$ & $98,51 \mathrm{a}( \pm 0,56)$ & $98,53 \mathrm{a}( \pm 0,41)$ & $97,58 \mathrm{a}( \pm 0,27)$ & $96,00 b( \pm 1,47)$ & $95,54 b( \pm 0,52)$ & 0,79 \\
\hline IRC (\%) & $-0,02$ & 100,00 & $-0,96$ & $-2,56$ & $-3,03$ & \\
\hline
\end{tabular}

Médias na mesma linha seguidos com letras iguais não diferem entre si (Tukey, $P>0,05)$.

Means in a row followed by the same letters did not differ (Tukey, $P<.05$ ).

na dieta. Esta tendência confirma as exigências do NRC (1993) de que dietas compostas com ingredientes de origem vegetal devem conter de 3,0 a $5,0 \%$ de fibra. Acima deste percentual de fibra bruta, observou-se comportamento semelhante aos verificados por Hilton et al. (1983), em experimento realizado com trutas, que verificaram menor digestibilidade aparente de todos os nutrientes da ração com maiores níveis de fibra bruta, e por Pereira-Filho (1989), que, trabalhando com carpa comum, concluiu que maior nível de fibra bruta tende a piorar o CDA da proteína bruta, e Dioundick \& Stom (1990), em estudo com a tilápia mossambica, quando $10,0 \%$ de celulose na dieta purificada proporcionou resultado de digestibilidade significativamente inferior.

Na Tabela 2, estão também apresentados os resultados das avaliações da digestibilidade aparente do extrato etéreo. Esses resultados, quando submetidos à análise de variância, revelaram, pelo teste $\mathrm{F}$, efeito significativo $(\mathrm{P}<0,01)$ entre tratamentos.

Semelhantemente ao ocorrido com a matéria seca, a digestibilidade aparente do extrato etéreo, também demonstrou efeito linear decrescente $(\mathrm{P}<0,05)$ com a equação $\hat{\mathrm{Y}}=99,7778-0,3396 \mathrm{FB}$, com coeficiente de determinação de $92 \%$. Essas médias, quando comparadas pelo teste Tukey, demonstraram que os CDA dos tratamentos T 2,5; $\mathrm{T}$ 5,0 e T 7,5 foram semelhantes entre si, o mesmo ocorrendo entre os tratamentos $\mathrm{T} 10,0$ e $\mathrm{T} 12,5(\mathrm{P}<0,05)$. Revelou, ainda, que esses dois grupos mostraram-se diferentes entre si, de forma significativa $(\mathrm{P}<0,05)$. Assim, a digestibilidade do extrato etéreo foi prejudicada com a presença de níveis maiores que $7,50 \%$ de fibra bruta.

Atribuindo-se 100,00\% à média do coeficiente de digestibilidade aparente do extrato etéreo do T 5,0 (IRC), constata-se (Tabela 2) que os tratamentos $\mathrm{T} 10,0$ e T 12,5 foram inferiores, respectivamente, em 2,56\% e 3,03\%. Esses resultados apresentam-se em concordância com Hilton et al. (1983) em estudo realizado com trutas, quando níveis de fibra bruta maiores que $10,0 \%$ prejudicaram de forma significativa a digestibilidade de todos os nutrientes da ração.

A interferência da fibra bruta na digestibilidade aparente da matéria seca, proteína bruta e do extrato etéreo das rações (Tabela 2) deve-se ao fato de esta alterar a taxa de utilização dos nutrientes, por modificar o tempo de esvaziamento gástrico, agir na motilidade e trânsito intestinal, por atuar na atividade das enzimas digestivas, pela captação de micelas de lipídios, e, graças à sua interação com a superfície da parede intestinal, interferir na absorção dos nutrientes (Madar \& Thorne, 1987).

As dietas empregadas neste estudo mostraram-se com semelhantes relações energia:proteína e ainda com níveis de nutrientes adequados aos objetivos propostos. Portanto, a ação significativa nos coeficientes de digestibilidade da matéria seca, proteína bruta e do extrato etéreo observada em tilápias do Nilo pode ser atribuída exclusivamente à ação da fibra bruta sobre o processo digestório dessa espécie. 
Os valores médios do tempo de trânsito (horas) das dietas purificadas no trato gastrintestinal de tilápias do Nilo, em função dos níveis de fibra bruta, encontram-se na Tabela 3.

As médias do tempo de trânsito revelaram efeito significativo $(\mathrm{P}<0,01)$ para tratamentos e, quando comparadas pelo teste Tukey, revelaram diferença significativa $(\mathrm{P}<0,05)$ entre tratamentos, sendo que todos diferiram entre si. Constata-se que o nível de fibra bruta resultou em tendência linear decrescente de tempo de trânsito gastrintestinal $(\mathrm{P}<0,05)$ com a equação $\hat{Y}=856,50-19,50 \mathrm{FB}$ e coeficiente de determinação de $97 \%$.

O tempo de trânsito gastrintestinal entre as dietas contendo 2,50 e $5,00 \% ; 5,00$ e $7,50 \%$ e $10,00 \%$ e $12,50 \%$ de fibra bruta diminuiu, respectivamente, em 47 minutos, 56 minutos e 1:26 horas.

A ação da fibra bruta sobre o tempo de trânsito gastrintestinal, verificada neste estudo, confirma os resultados observados por Shiau et al. (1988), com tilápias alimentadas com dietas purificadas, e ainda os estudos, com rações completas, apresentados por Hilton et al. (1983), com trutas (Salmo gairdneri); Zanoni(1996), com pacu (Piaractus mesopotamicus); e Garcia (1998), com piracanjuba (Brycon orbignyanus).

Para a tilápia do Nilo, na temperatura de $26,50^{\circ} \mathrm{C}$, o aumento da velocidade de trânsito observado entre os diferentes tratamentos, a partir da respectiva elevação da porcentagem de fibra bruta, quando comparado aos coeficientes de digestibilidade aparente da matéria seca, proteína bruta e do extrato

Tabela 3 - Valores médios do tempo (horas) de trânsito da dieta purificada no trato gastrintestinal de tilápia do Nilo, em função dos níveis de fibra bruta

Table 3 - Mean values for transit time, in hour, of purific diet in gastrointestinal tract of Nile tilapia, in function of the levels of crude fiber

\begin{tabular}{ccccccc}
\hline & \multicolumn{4}{c}{ Tratamento (\%) } & CV\% \\
& \multicolumn{5}{c}{ Treatment } & \\
\cline { 2 - 6 } & T2,5 & T 5,0 & T 7,5 & T 10,0 & T 12,5 & \\
\hline Hora & $13: 32$ a & $12: 45 \mathrm{~b}$ & $11: 49$ c & $11: 22 \mathrm{~d}$ & $9: 56 \mathrm{e}$ & 2,49 \\
\hline
\end{tabular}

a,bMédias, na linha, seguidas de letras diferentes, diferem $(\mathrm{P}<0,05)$ pelo teste Tukey.

$a, b$ Means, in a row, followed by different letters, differ $(P<.05)$ by Tukey test. etéreo (Tabela 2), demonstra que o teor de fibra bruta pode variar de $5,00 \%$ a $7,50 \%$. Esses resultados confirmam os obtidos por Hilton et al. (1983), Shiau et al. (1988), Pereira Filho (1989), Dioundick \& Stom (1990), Zanoni (1996) e Garcia (1998).

\section{Conclusões}

Níveis crescentes de fibra bruta, em dietas purificadas, interferem significativamente na digestibilidade aparente da matéria seca, proteína bruta e do extrato etéreo.

Níveis de até 5,00\% de fibra bruta não diminuem a digestibilidade aparente da matéria seca e da proteína bruta e 7,50\% de fibra bruta não diminuiu a digestibilidade aparente do extrato etéreo da dieta purificada pela tilápia do Nilo.

O aumento do teor de fibra bruta da dieta diminui significativamente a tempo de trânsito gastrintestinal.

\section{Literatura Citada}

ANDERSON, J.; JACKSON, A.J.; MATTY, A.J. et al. Effects of dietary carbohydrate and fibre on the tilapia (Oreochromis niloticus). Aquaculture, v.37, p.303-314, 1984.

AUSTRENG, G. Digestibility determination in fish using chromic oxide making and analysis of contents from different segments of the gastrointestinal tract. Aquaculture, v.13, p.265-75, 1978.

BOYD, C.E. Water quality in warmwater fish pond. 2 ed. Alabama: Auburn University, 1984. 359p.

CAstagnolli, N.; CYRINO, J.E.P. Piscicultura nos trópicos. 1.ed. São Paulo: Manuel, 1986. 143p.

DIOUNDICK, O.B.; STOM, D. Effects of dietary alfa cellulose on the juvenile tilapia, Oreochromis mossambicus (Peters). Aquaculture, v.91, n.3/4, p.311-315, 1990.

DUPREE, H.K.; SNEED, K.E. Response of channel catfish fingerlings to different levels of major nutrients in purified diets. Washington, D.C.: Bureau of Sport Fisheres and Wildlife U. S. Dept. Int., 1966. 21p. (Technical Paper, 9)

GARCIA, R.E. Fibra bruta no desempenho produtivo, digestibilidade aparente, trânsito gastrointestinal e morfologia do epitélio intestinal da piracanjuba (Brycon orbignyanus). Jaboticabal: Universidade Estadual Paulista, 1998. 55p. Tese (Doutorado em Aquicultura) - Universidade Estadual Paulista, 1998.

HILTON, J.W.; ATKINSON, J.L.; SLINGER, S.J. Effect of increased dietary fiber on the growth of raimbow trout (Salmo gairdinerri). Canadian Journal of Fisheries and Aquatic Sciences, v.40, p.81-85, 1983.

MADAR, Z.; THORNE, R. Dietary fiber. Progress in Food and Nutrition Science, v.11, p.153-174, 1987.

NATIONAL RESEARCH COUNCIL - NRC. Nutrient requirements of fish. Washington, D.C.: National Academy of Sciences, 1993. 102p. 
NOSE, T. Recent advances in the study of fish digestion in Japan. In: SIMPOSIUM ON FINFISH NUTRITION AND FISH FEED TECHNOLOGY, 1966, Belgrade. Proceedings... EIFAC/FAO, 1966, p.15 sc II-7.

PEREIRA-FILHO, M. Efeito de diferentes níveis de proteína e de fibra no desempenho, digestibilidade da fração protéica e características da carcaça de carpa (Cyprinus carpio L. 1758). Jaboticabal: Universidade Estadual de São Paulo, 1989. 96p. Tese (Doutorado em Aqüicultura) Universidade Estadual de São Paulo, 1989.

SHIAU, S.Y.; YU, H.L.; HWA, S. et al. The influence of carboxymethycellulose on growth, digestion, gastric emptying time and body composition of tilapia. Aquaculture, v.70, p.345-354, 1988.

SILVA, D.J. Determinação da celulose. Análise de alimentos (métodos químicos e biológicos). Viçosa, MG: Universidade Federal de Viçosa. 2.ed. 1990. p.20-22.

STOREBAKKEN, T. Binders in fish feeds I. Efeect of alginate and guar gun on growth, digestibility, feed intake and passage through the gastrointestinal tract of rainbow trout. Aquaculture, v.47, p.11-26, 1985.
WILLIANS, C.H.; DAVID, D.J.; IISMAA, O. The determination of chromic oxide in feces samples by atomic absorption spectrophotometry. Journal Agriculture Sciences, v.59, p.381-385, 1962.

ZANONI, M.A. Níveis de fibra bruta em dietas de crescimento do pacu (Piaractus mesopotamicus) HOLMBERG, 1887. Florianópolis: Universidade Federal de Santa Catarina, 1996. 66p. Tese (Mestrado em Aqüicultura). Universidade Federal de Santa Catarina, 1996.

Recebido em: 23/02/03

Aceito em: 01/07/04 